Short report

\title{
Inhibitory Effects of Musanga cecropioides on Noradrenaline and Potassium-Induced Contractions in Rat Thoracic Aorta
}

\author{
PETER I. AZIBA \\ Department of Pharmacology \& Therapeutics, College of Health Sciences, Olabisi \\ Onabanjo University, Ago-Iwoye.
}

Received: July, 2004

Accepted: October, 2004

\begin{abstract}
The pharmacological effects of Musanga cecropioides on rat thoracic aorta were examined in high $\mathrm{K}^{+}$ medium $(55 \mathrm{mM}), \mathrm{Ca}^{2+} 3 \mathrm{mM}$ ) induced vasoconstriction was inhibited by Musanga cecropioides in a concentration-dependent manner. The tonic contractions elicited by $\mathrm{KCl} 55 \mathrm{mM}$ were relaxed by Musanga and were more marked in $0.45 \mathrm{mM} \mathrm{Ca}^{2+}$ than $1.8 \mathrm{mM} \mathrm{Ca}^{2+}$ medium. NA -induced responses were antagonized non competitively by Musanga. NA- sustained contraction was relaxed, the relaxing effect of Musanga was not antagonized by indomethacin or methylene blue. It is concluded that Musanga relaxation of the rat aorta does not involve cyclo-oxygenase, nor cAMP pathway, but unique, unlike those of known classical vasodilators.
\end{abstract}

\section{Keywords:}

Musanga cecropioides, contraction, inhibition, Potassium, thoracic aorta

\section{INTRODUCTION}

Medicinal plants have been used as traditional remedies in Africa. In our previous studies, we reported that Musanga cecropioides didnot affect ach-induced contractile response but produced significant inhibition of the movement of the rat and rabbit gut smooth muscles, Aziba et al (2000). It is also reported to have a blood pressure lowerhig effect and it is used to procure painless childbirth, Adjanohoun et al (1989). These actio' prompted us to investigate in the present study, the effects of the aqueous extract of thleaves on the rat aorta on contractions induced NA an $\mathrm{K}$ on receptor and voltage mediated responses respectively.

\section{MATERIALS AND METHODS}

Male Wistar rats(200-350g) were killed by a blow on the head. The thoracic aorta was located, while excess fat and connective tissue was removed. The vessels were cut into strips according to Furchgott and Bhadrakom (1953). The contractile responses were rc $r$ ": $d$ isometrically using a force displacement transducer(FT-03,Grass) and the signals amplified with a polygraph (Grass, model
7D).the preparations were equilibrated for $1 \mathrm{hr}$ in the organ bath containing $10 \mathrm{ml}$ modified Krebs solution of the following composition (mM): $\mathrm{NaCl} 118, \mathrm{KCl} 1.2, \mathrm{CaC} 12$ 1.8, $\mathrm{MgCl} 2$ 1.2, $\mathrm{KH} 2 \mathrm{PO} 4 \quad 1.2, \quad \mathrm{NaHCO} 3$ 25 ,and glucose 11.7 .the tissue bath solution was bubbled with a 95\% 02,-5\% CO2 gas mixture which maintained the solution at $\mathrm{pH}$ of between 7.2-7.4. in some preparation, $\mathrm{K}$ Kreb's solution was prepared by replacing $\mathrm{NaC} 1$ with $\mathrm{KCl}$. The kreb solution with high potassium concentration was prepared by mixing the $\mathrm{K}$ krebs. The calcium free krebs solution was prepared by deleting Ca2duñng preparation of the Krebs solution. Drugs used were Noradrenaline hydrochloride (Sigma,st. Louis,MO USA) methylene blue (laboratory I-IBL reagent.

\section{Animals}

The adult albino rat $>6$ weeks old,Sprague Dawley strain) used in the experiment were supplied by the National institute of Medical Research, Yaba, Lagos, Nigeria. The animals were maintained in the Preclinical House in a well ventilated condition, under' constant temperature $\left(30^{\circ} \mathrm{C}\right)$ and humidity $50 \%$ and exposed to $12 \mathrm{hr}$ light dark cycle for 2 weeks before use. The animals were fed on 
standard livestock pellets (Pfizer, Nigeria Ltd), with free access to water and were treated ethically according to the guidelines for the treatment of experimental animal as determined by the animal council.

\section{Statistical Analysis}

The data obtained from this experiment were expressed as the mean (S.E.M) for nobservation. The value obtained in different groups were compared using test and probabilities of les than 5\% $(\mathrm{P}<0.05)$ were considered to indicate a significant difference.

\section{RESULTS}

\section{Effect of $M$. Cecropioides on $\mathrm{K}+$ Induced} Contractions

In high $\mathrm{K}^{+}(55 \mathrm{mM}) \mathrm{Ca}^{2+}$ free medium. The cumulative addition of $\mathrm{Ca}^{2+}>3 \mathrm{mM}$ to the aortic strip caused increase in contractile force. The maximum contraction $>3 \mathrm{mM}$ was $1.2+0.25 \mathrm{~g}$ ( $\mathrm{n}$ $=10$ ). After incubating the strip in musanga (10 $1000 \mathrm{mg} / \mathrm{ml}$ ) for 10 minutes, inhibited contraction in a concentration dependent manner (fig IA), the $I_{50}$ value was calculated to be 1 5.increasing the incubation time did not cause any pronounced inhibitory action of Musanga.(fig 1B) low doses inhibited the high $\mathrm{K}^{+}$induced $\mathrm{Ca}^{2+}$ dependent contraction, suggesting action on voltage operated $\mathrm{Ca}^{2+}$ channel effect.

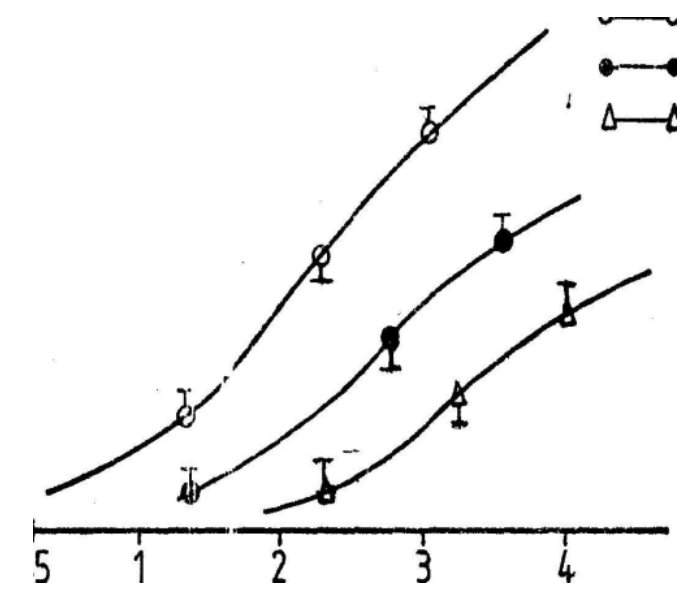

Effects of Musanga on Noradrenaline
Induced Contraction

Cumulative addition of NA ( $5 n M-2 n M)$, caused increase of contractions of rat aorta. The maximum contraction induced by $10 \mathrm{nM}$ noradrenaline was $1.56 \pm 0.12 \mathrm{~g}(\mathrm{n}=10)$. Musanga produced a non competitive blockade of noradrenaline induced contraction. This relaxing action of Musanga was not blocked by either methylene blue 40nM or indomethacin 10nM. Pre-incubated aorta in Nifedipine for 10 minutes, $\mathrm{K}^{+} 55 \mathrm{mM}$ induced contraction was completely blocked while it had no effect on NA induced contractions (Fig 2 ).
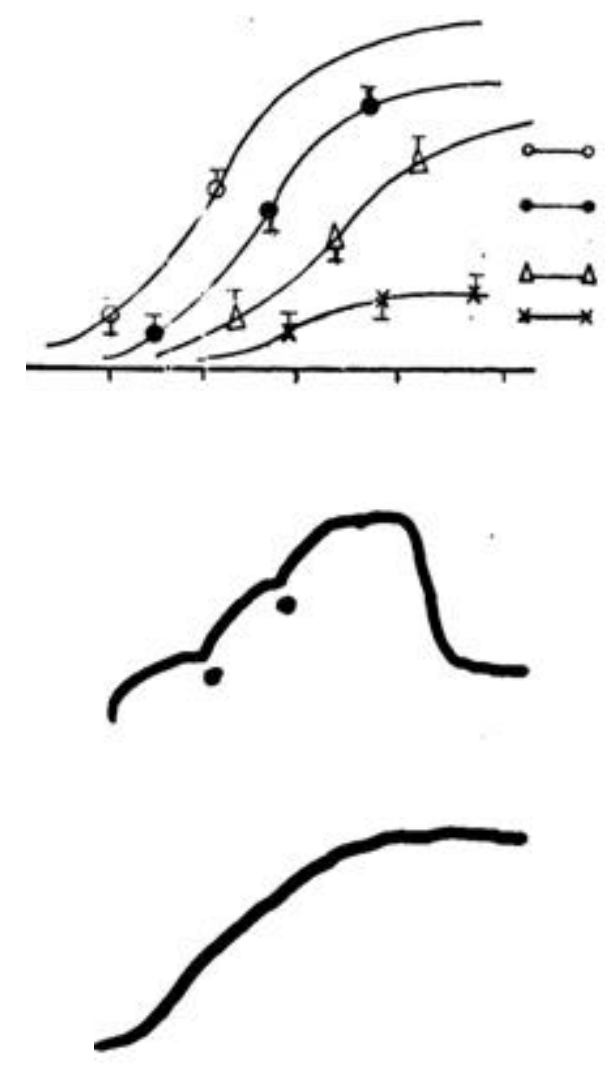

\section{DISCUSSION}

Rat aorta pre-treated with Musanga cecropiodes in this study inhibited contractile responses to Noradrenaline and high $\mathrm{Ca}^{2+} 55 \mathrm{mM}$ ), it also caused the relaxation of the blood vessel when Musanga was added to NA induced sustained contractions. Contraction of Vascular smooth muscle requires increase in free cytosolic $\mathrm{Ca}^{2+}$ (Karaki and Weis 1979), the actions of Musanga was more enhanced in low medium Ca2 $0.45 \mathrm{mM}$, then high $\mathrm{Ca}^{2+}$ medium $1.8 \mathrm{mM}$ in this study. The $\mathrm{K}^{+}$induced contraction of the smooth muscle arise from increased $\mathrm{Ca}^{2+}$ influx through voltage dependent $\mathrm{Ca}^{2+}$ channels (Karaki and Weis 1979). Bay K 8044, a derivative of Nifedepine, a known Ca2entry facilitator did affect this action of Musanga. The inhibitory effect of musanga was much reduced in high $\mathrm{Ca}^{2+}$ medium $1.8 \mathrm{mM}$. . The tonic tension in response to Noradrenaline results from $\mathrm{Ca} 2$ entry through receptor operated calcium channel (Bolton 1979). The inability of musanga to inhibit the actions of indomethacin and methyle ne blue, rules out, the possibility of the plant action involving cyclo-oxygenasse nor cyciic AMP pathways. The totality of this result indicated that the inhibitory effects of Musanga cecropioides on the contractile responses caused by high $\mathrm{K}^{+}$ or NA are not due to increase in cyclic 
nucleotide. Yang- Chong et al (1993) Musanga relaxes the rat aorta in a unique manner different from the known vasodilators and its actions on receptor is not specific since on receptor mediated responses, it suppressed maximum contractile response induced by Noradrenaline and high $\mathrm{K}^{+}$in a non competitive manner.

\section{REFERENCES:}

Aziba P. I. and Gbile, Z. O. (2000): Pharmacological screening of aqueos extract of Musanga Cecropioides. Fitoterapia 71, 143-146 Adjanthoun E. J, Alji A.M, Ake Assi (1989), In medicine traditionelle et pharmacopea. Paris ACCT, 148-149

E-mail:peteraziba@yahoo.com
Bolton T. B (1979) Mechanisms of action of transmitters and aher substances on smooth muscle Physiol. Rev. 59. 607- 718.

Furchgott, R. F and Bhadrakon, A. (1953) Reactions of strips of rabbit aorta in ephridine, Isoproterenol,, sodium nitrite and other drugs. J. Pharmacol. Ext. Ther. 142:39-58

Karaki H, Weiss, G. B (1984) Calcium channels in smooth muscle Gastroenterology 87: 960-970 Popescu L. M, Panoin C, Hinescu M, Narto U (1985) The mechanism of CGMP-induced relaxation in vascular smooth muscle. Eur Jour. Pharmacol, 107:393-394

Zsoter T. T, Henein N. F Woldhinsky C, (1997). The effect of Sodium nitropusside on the uptake and efflux of $45 \mathrm{Ca}^{2+}$ from rabbit and rat vessels. Eur. J. Pharmacol 45: 7-12 